\title{
ATTRACTING AND SELECTING: WHAT PSYCHOLOGICAL RESEARCH TELLS US
}

\section{Ann Marie Ryan and Nancy T. Tippins}

HR practitioners often have misperceptions regarding research findings in the area of employee selection. This article reviews research on what selection tools work, what recruitment strategies work, how selection-tool use relates to workforce diversity, and what staffing and recruiting processes lead to positive applicant perceptions. Knowledge and implementation gaps in these areas are discussed, and key research findings are presented. (C) 2004 Wiley Periodicals, Inc.

HR professionals are challenged to address an organization's varied needs when it comes to recruiting and staffing. One often hears that the proposed solution to a "people problem" is to do a better job in the recruiting process of attracting better people, do a better job in the hiring process of identifying future stars and "weeding out" the problems, and do a better job of attracting and selecting a more diverse workforce. Moreover, organizational demands require that HR professionals accomplish these goals quickly and in a cost-effective manner. HR professionals are continually called upon to come up with new strategies for attraction, new tools for selection, and new ways to enhance workforce diversity, while incorporating the sometimes competing needs and views of varied stakeholders - the hiring managers, the applicants, the legal department, recruiters, labor unions, other external groups, and so on.

While recruitment and staffing strategies and tools are sometimes prone to fads, there is a substantial body of research to guide HR professionals in meeting these challenges. In this article, we will discuss four areas where this research can provide some clarity regarding what works and what does not, yet where the research often gets overlooked. These four areas are (1) what selection tools work, (2) what recruitment strategies work, (3) how selection-tool use relates to workforce diversity, and (4) what staffing and recruiting processes lead to positive applicant perceptions. Our focus and 
We contend

that a great deal of the research in the staffing and recruiting area has not been widely embraced by the HR practitioner. examples will encompass both internal and external staffing situations.

We contend that a great deal of the research in the staffing and recruiting area has not been widely embraced by the HR practitioner. For example, Rynes, Brown, \& Colbert (2002) reported that some of the most common misperceptions of HR practitioners were in the area of selection. There are several reasons for these gaps. First, research is not well disseminated and remains buried in jargonladen pages of academic journals (Rynes, Colbert, \& Brown, 2002), rather than translated into "something useful" and made accessible to HR executives (hence, the purpose of this special issue). Second, research is focused on the situation in the abstract and seldom takes into account the many contextual factors (e.g., budget, time constraints) an HR practitioner must juggle in making decisions about what tools and strategies to employ. Third, many HR professionals in staffing functions and particularly those in tight labor markets face constant pressure to deliver qualified candidates quickly and lack the time to create new recruiting and selection programs that take into account current research findings. Fourth, some stakeholders' perceptions and goals for hiring are not compatible with the research (Rynes, Colbert, \& Brown, 2002), making it difficult for the HR professional to incorporate the research findings into a hiring program. Fifth, many HR professionals find myriad legal requirements confusing. Consequently, they avoid testing and other systematic approaches to selection despite the research because they believe erroneously that testing will create legal problems rather than solve them. In this article, we hope to close some of these gaps by presenting some key, agreed-upon findings regarding staffing and discussing the practical steps one must go through to effectively implement these findings.

\section{Selection Tools}

After over a century of research on methods of selecting employees, there is a considerable body of knowledge regarding what works well across jobs and organizations and what does not, as well as substantial research on tools for specific types of positions (e.g., managerial, customer service). However, wide gaps between knowledge and practice exist in many organizations. For example, Rynes, Colbert, and Brown (2002) reported that $72 \%$ of the HR managers they surveyed thought that, on average, conscientiousness is a better predictor of employee performance than intelligence, whereas the reverse is actually true. Similarly, they found that the majority of respondents believed that companies that screen job applicants for values have higher employee performance than those that screen for intelligence, another practice that is not supported by the research. Another example provided by Rynes, Brown and Colbert (2002) is the common misperception that integrity tests do not work because individuals lie on them, when in reality these tests can predict job performance despite any tendencies of candidates to misrepresent themselves.

In our work with organizations, we run across many hiring managers who make blanket statements that testing is not worthwhile, despite the fairly substantial body of research that demonstrates that testing can be very useful. Even when presented with evidence of strong relationships between test scores and job performance, some managers are unwilling to concede that structured selection programs are not just good ways to select employees; they are better than other less structured alternatives. The power of "gut instinct" and "chemistry" seems to override the hard data and rational arguments.

What do we know about which tools are most useful? Table I provides a summary of the basic characteristics of various tools (i.e., validity, costs, and group differences), based on the current body of research. The first column provides a listing and brief description of common measures used in staffing situations. The second column reports "validity," which is a statistical measure ranging from 0 to 1.00 of the relationship between test scores and a criterion-in this case, job performance. Note that these values represent likely upper-limit values in that they are not reduced by factors that would lower values obtained in operation (e.g., unreliability in the measurement of job performance, re- 
striction in range of scores). While larger numbers generally indicate more accurate prediction statistically, even low numbers (i.e., less than .20) increase the accuracy of prediction, particularly when the applicant pool is large and the number selected is relatively small. The third column provides overall estimates of the costs to develop and deliver each instrument relative to other selection tools. Information about group dif- ferences is contained in the fourth column of Table I. The data are presented in terms of standardized group differences (i.e., all data are presented on the same numeric scale). "B/W: -1.0 " indicates that in the research reported, blacks scored one standard deviation below the mean of whites.

There are some key points to keep in mind when applying Table I to a specific organizational context. First, the table presents

\section{TABLE I Tool Comparison}

Tool

Cognitive ability tests measure mental abilities such as logic, reading comprehension, verbal or mathematical reasoning, and perceptual abilities, typically with paper-and-pencil or computer-based instruments.

Structured interviews measure a variety of skills and abilities, particularly noncognitive skills (e.g., interpersonal skills, leadership style, etc.) using a standard set of questions and behavioral response anchors to evaluate the candidate.

Unstructured interviews measure a variety of skills and abilities, particularly noncognitive skills (e.g., interpersonal skills, leadership style, etc.) using questions that vary from candidate to candidate and interviewer to interviewer for the same job. Often, specific standards for evaluating responses are not used.

Work samples measure job skills (e.g., electronic repair, planning and organizing), using the actual performance of tasks that are similar to those performed on the job. Typically, work samples use multiple, trained raters and detailed rating guides to classify and evaluate behaviors.

Job knowledge tests measure bodies of knowledge (often technical) required by a job, often using formats such as multiple-choice questions or essay-type items.

Conscientiousness measures the personality trait "conscientiousness," typically with multiple-choice or true/false formats.

Biographical information measures a variety of noncognitive $\quad .35$ skills and personal characteristics (e.g., conscientiousness, achievement orientation) through questions about education, training, work experience, and interests.

$\begin{array}{llll}\text { Validity }^{a} & \begin{array}{l}\text { Costs } \\ \text { (development/ }_{\text {administration) }}^{b}\end{array} & \begin{array}{l}\text { Group } \\ \text { differences }^{c}\end{array} & \text { Source } \\ \text { Low/low } & \text { B/W: }-1.0 & \text { Hough, Oswald, } \\ & & \text { H/W: }-.5 & \text { \& Ployhart, 2001 } \\ & & \text { A/W: } .2 & \\ & & \text { W/M: }: & \\ & & \text { B/W: }-.23 & \text { Huffcutt \& Roth, } \\ .51 & \text { High/high } & & 1998\end{array}$

Low/high

$\mathrm{B} / \mathrm{W}:-.32$

$\mathrm{H} / \mathrm{W}:-.71$

Huffcutt \& Roth, 1998

High/high

B/W: .38

Schmitt, Rogers, Chan, Sheppard, \& Jennings, 1996

High/low

B/W: .38

Schmitt et al., 1996

Low/low

B/W: -.06

$\mathrm{H} / \mathrm{W}:-.04$

Hough et al.,

A/W: -.08 2001

W/M: .08

High/low

B/W: -.78

for grades

B/W: -.27

biodata

H/W: .08

biodata

W/M: -.15

biodata
Roth \& Bobko, 2000

Hough et al., 2001

(continued) 
TABLE I Tool Comparison (continued)

Tool

Situational judgment tests measure a variety of noncognitive skills by presenting individuals with short scenarios (either in written or video format) and ask what would be their most likely response or what they see as the most effective response.

\begin{tabular}{|c|c|c|c|}
\hline Validity $^{a}$ & $\begin{array}{l}\text { Costs } \\
\text { (development/ }^{\text {administration })^{b}}\end{array}$ & $\begin{array}{l}\text { Group } \\
\text { differences }^{c}\end{array}$ & Source \\
\hline .34 & High/low & $\begin{array}{l}\text { B/W: }-.61 \\
\text { on paper } \\
\text { and pencil } \\
\text { B/W: }-.43 \\
\text { on video } \\
\mathrm{H} / \mathrm{W}:-.26 \\
\text { on paper } \\
\text { and pencil } \\
\mathrm{H} / \mathrm{W}:-.39 \\
\text { on video } \\
\mathrm{W} / \mathrm{M}: .26 \\
\text { on paper } \\
\text { and pencil } \\
\text { W/M = .19 } \\
\text { on video }\end{array}$ & $\begin{array}{l}\text { Hough et al., } \\
2001\end{array}$ \\
\hline
\end{tabular}

.41
Low/low

to a person's honesty, dependability, trustworthiness, and reliability, typically with multiple-choice or true/false formats.

Assessment centers measure knowledge, skills, and abilities through a series of work samples/exercises that reflect job content and types of problems faced on the job, cognitive ability tests, personality inventories, and/or job knowledge tests.

Reference checks provide information about an applicant's past performance or measure the accuracy of an applicant's statements on the résumé or in interviews by asking individuals who have previous experience with a job candidate to provide an evaluation. on video

B/W: $-.04 \quad$ Hough et al.,

$\mathrm{H} / \mathrm{W}: .14 \quad 2001$

A/W: .04

W/M: . 16

High/high

Varies by

exercise;

-.02 to -.58

Goldstein, Yusko, \& Nicolopoulos, 2001

\footnotetext{
a Source for validity coefficients: Schmidt \& Hunter (1998), except Situational Judgment Test validity, from McDaniel, Morgeson, Finnegan, Campion, \& Braverman (2001). Validity values range from 0 to 1.0, with higher numbers indicating better prediction of job performance.

bThe labels "high" and "low" are designations relative to other tools rather than based on some specific expense level.

'Values are effect sizes expressed in standard deviation units. Higher numbers indicate a greater difference; negative values mean the first group scores lower. $\mathrm{B} / \mathrm{W}$ is black/white difference; $\mathrm{H} / \mathrm{W}$ is Hispanic/white difference; $\mathrm{A} / \mathrm{W}$ is Asian/white difference; W/M is female/male difference.
}

potential values and exact results will depend upon the specific situation present. As noted earlier, these are not operational values but estimates without the influence of some factors that likely will depress values obtained in a given setting. Second, any hiring manager or researcher will agree that the number-one criterion for a useful selection device is that it provides information on who will be a good employee. In research terms, this translates into which devices have good validity for pre- dicting work outcomes, such as job performance, turnover, and absenteeism. However, beyond this key objective, there are a number of other factors that may influence tool usefulness in practice that need to be considered in making choices. HR managers will be concerned about issues such as the cost to develop the tool and use it, the ease of administration, and the likelihood of adverse impact (i.e., disproportionate hiring rates for different ethnic or gender groups). However, 
rather than considering validity, costs, and subgroup differences as tradeoffs, choices among valid tools should involve cost and subgroup differences as additional considerations only when an acceptable level of validity has been established. That is, it never makes sense to employ a tool without supporting validity evidence-regardless of how cheap, how low the adverse impact, or how easy to administer. A test with low validity will not result in good hiring decisions and will be much more costly in the long run. Thus, the validity column in Table I should always be the first factor in tool choice.

To that primary consideration, we add a number of others. First, specific tools vary in usefulness according to how well developed they are-a poorly developed tool will not function at the optimal level suggested by the table. For example, a structured interview may have a validity of .51 if interviewers are trained, adhere to the standard set of questions, and use the behavioral anchors to rate candidate responses. Deviations from these "best practices" for interviews may result in considerably lower validity (see Posthuma, Morgeson, \& Campion, 2002 for a recent review of research on interviewing).

Second, some selection tools are not appropriate for a particular situation. For example, job knowledge tests may not be appropriate for an entry-level position if they tap knowledge easily acquired on the job and not needed at the time of hire (Schmitt \& Chan, 1998). Similarly, some personality measures are inappropriate for employee-selection contexts, and some personality traits do not have much relation to job performance (see Barrick, Mount, \& Judge, 2001 for a review of the research evidence on personality testing). An experience with an inappropriately applied tool can lead to a generalization about the usefulness of all personality testing that is flawed. Another reason for the research-practice gap may be managers making judgments about a category of tools for all positions based on negative experiences with a specific tool (e.g., a poorly developed tool or a welldeveloped tool used inappropriately) for a specific position.

Further, to maximize the effectiveness of a selection system, one needs to consider how well tools might work in combination (Society for Industrial and Organizational Psychology, 2003). In most cases, measuring more job-related skills and abilities results in better predictions of overall job performance. Schmidt and Hunter (1998) noted that combining a general mental ability measure with a structured interview or with a work sample is likely to yield the highest composite validity. Determining the optimal number of tools for any given situation will involve considering how each tool enhances prediction relative to its additional expense and time requirements.

Finally, the usefulness of a selection tool in any given situation will require evaluating context-specific factors not presented in the table, such as the selection ratio (number of candidates hired relative to the number of candidates who applied), hiring cycle time, costs of a selection error (e.g., cost of replacement, error, lost opportunities), and so on. Higgs, Papper, and Carr (2000) noted eight "drivers of selection process success." Table I presents information on two of these-empirical validity and expense. We discuss two others (face validity and candidate reactions) in the section on applicant reactions. The other drivers-selection ratio (how many applicants per position), marketability (getting people in the organization to use the tools), timeliness (feedback to applicants and hiring managers), and management of the process (selection system administrator ability and credibility)_are all context-specific and may be more challenging for some HR managers than others. Further, Tippins (2002) noted that putting a selection system into use involves a host of implementation issues-decisions about the ordering of process elements, the ways in which information will be combined, the use of technology in delivery of tools, the training of tool users, policies (e.g., waivers), the database structure and access, and communications about the system-all of which contribute to the success or failure of a selection system.

Another contributor to the researchpractice gap in selection-tool use is the lack of information regarding the business reasons for tool use. HR managers need information on selection tools in the language of
It never makes sense to employ a tool without supporting validity evidenceregardless of how cheap, how low the adverse impact, or how easy to administer. 
Research has

demonstrated

that firms using

effective

staffing

practices (e.g.,

conduct studies

of recruiting

source yield

and validation

studies for tools

used; use

structured

interviews,

cognitive ability

tests, and

biodata tools)

have higher

levels of annual

profit, profit

growth, sales

growth, and

overall

performance

(Terpstra \&

Rozell, 1993). a business case-how individual-level prediction translates to organizational-level results. Research has demonstrated that firms using effective staffing practices (e.g., conduct studies of recruiting source yield and validation studies for tools used; use structured interviews, cognitive ability tests, and biodata tools) have higher levels of annual profit, profit growth, sales growth, and overall performance (Terpstra \& Rozell, 1993). Despite the research findings, researchers have had difficulty presenting projections about organizational-level outcomes in ways that are understood, believed, and accepted by managers (Latham \& Whyte, 1994; Macan \& Highhouse, 1994; Whyte \& Latham, 1997). While some researchers (e.g., Hazer \& Highhouse, 1997) have begun to examine ways of presenting utility information so that it is seen as more credible by managers, building a better business case for selection-tool use will also require research on how to communicate this information effectively (Jayne \& Rauschenberger, 2000).

\section{Recruitment Strategies and Methods}

Research on recruitment also does not always translate into practice. Taylor and Collins (2000) concluded that although recruitment practice continues to evolve in creative ways, there could be a better research-practice connection. For example, Rynes, Colbert, \& Brown (2002) found that only half of the HR managers they surveyed knew that applicants sourced from job ads have higher turnover than those who are referrals. Table II provides an abbreviated list of principles from recruitment research presented by Taylor and Collins. We selected research findings that are related to considerable research-practice gaps, and we have added ways in which these findings could be implemented in practice.

Even armed with knowledge of these issues, HR managers often find themselves facing an implementation gap-they cannot apply what they know. Reasons for this gap include the ever-present cost concerns. Recruiting practices and budgets are often driven by the labor market cycle. For example, one needs to use any and all methods of applicant sourcing in times of a tight labor market where few individuals are looking for jobs. Further, competitor strategies can lead an organization to change practice simply to attract the best applicants. For example, during the heady days of Silicon Valley, hiring required companies to make offers on the spot and give large signing bonuses. However, as Breaugh and Starke (2000) have noted, the key themes of recruitment research are informativeness and personable treatmentincorporating these elements into every aspect of the recruiting process should not be something affected by cycles in the market or competitor behavior.

\section{Diversity and Hiring Practices}

HR managers must be concerned with how the use of certain tools and recruitment practices may affect workforce diversity. A glance at the research summary tables presented thus far suggests that using cognitive ability tests and employee referrals are very effective hiring and recruitment strategies; yet both may affect organizational diversity in adverse ways. HR professionals must strive for achieving two goals: identifying capable candidates and creating a diverse workplace.

Psychological researchers have been very interested in how to simultaneously achieve the goals of workforce effectiveness and workforce diversity, and much research has been conducted on how to minimize adverse impact in hiring practices while using a process with high validity (see Sackett, Schmitt, Ellingson, \& Kabin, 2001 for a summary). Table III presents common methods of adverse impact reduction that have been advocated in practice and information on whether the research is supportive of those practices. In addition, we have coded the practice "-", " 0 ", or "+" depending on the extent to which the practice hinders the effort to reduce adverse impact, has no effect on adverse impact, or improves it.

As Table III shows, there are some strategies that can be employed to reduce adverse impact and appear to work. But the research also suggests that adverse impact will be difficult to eliminate entirely without re- 


\section{TABLE II Recruitment Research and Application Gaps}

Research Finding ${ }^{a}$

Recruitment sources affect the characteristics of applicants attracted.

Recruitment materials have a more positive impact if they contain more specific information.

Organizational image influences applicants' initial reactions to employers.

Applicants with a greater number of job opportunities are more attentive to and more influenced by early recruitment activities than those with fewer opportunities (i.e., less marketable individuals).

Recruiter demographics have a relatively small effect on applicants' attraction to the organization.

Realistic job previews (e.g., brochures, videos, group discussions that highlight both the advantages and the disadvantages of the job) reduce subsequent turnover.

Applicants will infer job and organizational information based on the organizational image projected and their early interactions with the organization if the information is not clearly provided by the organization.

Recruiter warmth has a large and positive effect on applicants' decisions to accept a job.

Applicants' beliefs in a "good fit" between their values and the organization's influence their job-choice decisions.
Practical Applications

Use sources such as referrals (e.g., from current employees) that yield applicants less likely to turnover and more likely to be better performers.

Provide applicants with information on aspects of the job that are important to them, such as salary, location, and diversity.

Ensure all communications regarding an organization provide a positive message regarding the corporate image and the attractiveness of the organization as a place to work.

Ensure initial recruitment activities (e.g., Web site, brochure, on-campus recruiting) are as attractive to candidates as later activities.

Worry less about matching recruiter/applicant demographics and more about the content of recruiting messages and the organization's overall image in terms of diversity.

Provide applicants with a realistic picture of the job and organization, not just the positives.

Provide clear, specific, and complete information in recruitment materials so that applicants do not make erroneous inferences about the nature of the job or the organization as an employer.

Individuals who have contact with applicants should be chosen for their interpersonal skills.

Provide applicants with accurate information about what the organization is like so that they can make accurate fit assessments.

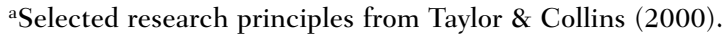

ducing the validity of a selection program (Sackett et al., 2001). The extent of adverse impact reduction is influenced by a complex set of factors, such as the nature of the applicant pool, the selection ratio, the manner in which tools are used, and the degree of relationship among the tools used. As Table III indicates, research does support considering a broader spectrum of desired work outcomes as the criteria for success, using noncognitive predictors exclusively, actively diversifying the applicant pool with qualified individuals, or appropriately orienting and motivating applicants as ways to lower the adverse impact of a selection system. The research does not provide strong support for other common practices such as providing coaching and orientation programs, banding scores without having preferential selection, removing culturally biased items, altering formats, or increasing time limits. It is important to note that while research does not fully support combining a tool with higher adverse impact with one having lower adverse impact to mitigate overall adverse impact of the selection process, the research does support broadening the selection process so that both task performance and so-called "contextual" performance are predicted. Thus, an action such as adding a tool that measures competencies related to contextual performance and has less adverse impact may have a mixed effect on overall adverse impact. 
TABLE III Practices Used To Reduce the Adverse Impact of a Selection System and Research Support

Common Practices To

Reduce

Adverse Impact

Target recruitment strategies toward qualified minorities.

Use a selection system that focuses + on predicting performance in areas such as helping coworkers, dedication, and reliability, in addition to task performance.

Use a tool with high adverse $0 /-$ impact and good validity in combination with a tool with low adverse impact to reduce the overall adverse impact of the system.

Provide orientation and preparation 0 programs to candidates.

Remove cognitive ability testing $+/ 0$ from the selection process.

Use banding of test scores.

Use tools with less adverse impact $\quad+/ 0$ as screening devices early in the process and those with greater adverse impact as later hurdles in the process.

Change the more negative test 0 taking perceptions of minority test takers about test validity, thereby increasing motivation and performance.

Identify and remove culturally

\author{
Degree of Support \\ for Practice \\ in Literature
}

biased test items.

\section{Research Findings}

Characteristics of the applicant pool (e.g., proportion of minorities, average score levels of minorities) have the greatest effect on rates of adverse impact (Murphy, Osten, \& Myors, 1995); changing these characteristics through targeted recruitment should help reduce adverse impact. However, simply increasing numbers of minorities in the pool will not help unless one is increasing numbers of qualified recruits.

If the overall performance measure weights contextual performance (e.g., helping, reliability) more than task performance and the tests in a battery are uncorrelated, a test battery designed to predict this definition of overall performance will have smaller levels of adverse impact (Hattrup, Rock, \& Scalia, 1997; Sackett \& Ellingson, 1997). Weighting task performance less than contextual performance in the overall performance measure will make cognitive ability less important in hiring and will lead to less adverse impact (Hattrup et al., 1997).

The degree to which adverse impact is reduced by combining tools with lower adverse impact is greatly overestimated; reductions may be small or the combination may actually increase adverse impact

(Sackett \& Ellingson, 1997).

Coaching and orientation programs have little effect on size of group differences but are well received by examinees (Sackett et al., 2001).

Using only noncognitive predictors (e.g., interview, conscientiousness, biodata) will lead to significantly reduced adverse impact, but significant black/white differences will remain (Bobko, Roth, \& Petosky, 1999). Also, cognitive ability tests are among the most valid predictors of job performance, and their removal may result in a selection system that is less effective.

The use of banding has less effect on adverse impact than the characteristics of the applicant pool (Murphy et al., 1995). Substantial reduction of adverse impact through banding only occurs when minority preference within a band is used for selection (i.e., preferential selection is employed; Sackett \& Roth, 1991).

Using tools with less adverse impact as screening devices early in the process and those with greater adverse impact later in the process will aid minority hiring if the selection ratio is low, but will not have much effect if the selection ratio is high (i.e., few applicants per position; Sackett \& Roth, 1996).

May provide a very small reduction in adverse impact (Ployhart \& Ehrhart, 2002; Sackett et al., 2001).

Research suggests that clear patterns regarding what items favor one group or another do not exist and that removal of such items has little effect on test scores; however, item content should not be unfamiliar to those of a particular culture and should not be more verbally complex than warranted by job requirements (Sackett et al., 2001).

(continued) 
TABLE III Practices Used To Reduce the Adverse Impact of a Selection System and Research Support (continued)

Common Practices To

Reduce

Adverse Impact

Use other modes of presenting

test stimuli than multiple-choice, paper-and-pencil testing

(e.g., video).

\author{
Degree of Support \\ for Practice \\ in Literature Research Findings \\ 0 \\ Changes in format often result in changes in what is actually \\ measured and can be problematic; in cases where a format change \\ was simply that (e.g., changed format without affecting what was \\ measured), there was no strong reduction in group differences \\ (Sackett et al., 2001).
}

Use portfolios, accomplishment $\quad+$ /0

records, and performance

assessments (work samples) instead

of paper-and-pencil measures.

Relax time limits on timed tools. $\quad 0$
Evidence suggests group differences may not be reduced by realistic assessments, and reliable scoring of these methods may be problematic (Sackett et al., 2001). Well-developed work samples may have good validity and less adverse impact than cognitive ability tests (see Table I).

Research indicates that longer time limits do not reduce subgroup differences, and may actually increase them (Sackett et al., 2001).
While many of the rationales for the gap between research and practice apply to the specific gap involving adverse impact and diversity research and practice, one rationale is particularly relevant here. The HR professional confronts an extremely perplexing dilemma. The two goals of identifying good candidates accurately and building a diverse workforce are difficult to reconcile. Some of the more effective strategies, such as using only noncognitive measures, also reduce the validity of the selection process. Thus, the HR professional can be faced with a difficult choice-maximizing the accuracy of predictions made on the basis of tests or reducing adverse impact. In addition, it merits noting that no one approach works, and the HR manager must pursue several avenues to achieve these goals. Because the research presents no easy solutions, the reluctance of HR professionals to employ any of these ideas is understandable.

\section{Applicant Perceptions}

HR managers are often concerned that the tools and recruitment approaches best supported by research might serve to "turn off" the most desirable applicants. That is, high performers can be more selective about where they choose to work. A legitimate concern of the HR professional is the extent to which research takes into account how applicants feel about the various tools and strategies recommended. Over the last decade, there have been considerable advances in our knowledge of what applicants prefer and what they see as fair and unfair and what can be done to mitigate negative reactions of applicants (see Ryan \& Ployhart, 2000 for a review). After all, a hiring process is an evaluative one, and many individuals will walk away without a job. While the research in this area is nascent, there are some basic practical steps that HR managers can consider in designing and implementing selection and recruiting practices.

Table IV provides some key suggestions arising from basic psychological research on perceptions of justice, ways to mitigate negative perceptions of a negative outcome (i.e., a rejection letter), and best approaches to explaining the process and decisions to ensure the most positive perceptions possible.

One overall conclusion from this area of research is that strong generalizations re- 


\section{TABLE IV Research on Applicant Perceptions ${ }^{\mathrm{a}}$}

\section{Research Finding}

Applicants have more favorable attitudes toward selection processes when they are given an explanation as to how the tools are related to future job performance.

Applicants prefer selection tools that they perceive to be related to the job.

Procedures that are seen as consistently administered are viewed as more fair.

Applicants feel negatively about organizations when they perceive recruiters to be misleading or believe they were not treated with sincerity.

Applicants prefer processes that allow time for two-way communication.

Letters of rejection without any justification are perceived more negatively than those in which an explanation is provided.

Failure to receive timely feedback is a leading contributor to perceptions of unfairness.
Practical Applications

Provide applicants with an overview of what the selection tool is designed to assess.

Use tests that are face-valid. If tests are not face-valid, provide clear information on the job relevancy to applicants.

Make sure selection tools are consistently administered and legitimate deviations (e.g., accommodations for ADA) are clearly explained to all applicants.

Treat applicants with honesty and respect.

Ensure applicants have an opportunity at some point in the process for face-to-face interaction, and make them aware of that opportunity if early stages of the selection process are computerized.

Deliver informative feedback on hiring decisions.

Provide feedback regarding selection and hiring decisions in a timely manner.

${ }^{a}$ Information from Gilliland \& Cherry (2000).

\section{TABLE V Audit Questions}

- Have we determined which applicant groups to target?

- Are efforts being made to recruit a diverse applicant pool?

- Are efforts being made to have a low selection ratio (i.e., a low number of people selected relative to the total number of applicants)?

- Are we considering combinations of tools to achieve the highest validity and lowest adverse impact?

- Have we considered how our ordering of tools affects validity and adverse impact?

- Are we considering all aspects of job performance in choosing tools?

- Have we determined which recruiting sources provide the best yield?

- Are we providing applicants with the specific information they desire?

- Have we selected recruiters who are warm and friendly?

- Is appropriate attention being given to early recruitment activities?

- Are applicants being processed quickly?

- Do we solicit feedback from applicants on satisfaction with the staffing process?

- Are applicants being provided with information about the job-relatedness of the selection process?

- Are applicants provided with accurate information on which to judge their fit with the position?

- Do we have evidence that selection procedures are job-related?

- Are applicants treated with respect?

- Is the selection process consistently administered?

- Does the process allow for some two-way communication?

- Is feedback provided to applicants in an informative and timely manner? 
garding applicant preferences for tools should not be made. For example, we often hear opinions that applicants will react negatively to biodata questions, find integrity tests and personality tests invasive, view cognitive ability tests as not job-relevant, find assessment centers to be taxing and overkill, and see structured interviews as restrictive. Overall, the research suggests that applicants will not react negatively to tools that are well developed, job-relevant, and used in selection processes in which the procedures are appropriately applied, decisions are explained, and applicants are treated respect- fully and sensitively-these concerns apply to all tools equally.

The gaps between research and practice in the area of applicant perceptions can be attributable to many factors, including the ones already cited. However, an additional important reason for the wide gap may be the lack of accurate knowledge about the entire applicant pool and erroneous assumptions about applicant preferences. It is often difficult to get information from the entire range of applicants. Many HR managers are reluctant to solicit feedback from applicants who are not hired and hear only from the dis-

\section{TABLE VI Questions for Experts}

\section{Education:}

- What is your highest degree?

- From what institutions are your degrees?

- What kind of education and training in test development, measurement, validation, and statistics do you have?

- Were the courses for credit? From what institution were they granted?

Comment: Ask about a consultant's educational background. A PhD in industrial and organizational psychology or a closely related field is often a fundamental requirement for competence in testing work. While continuing education courses can strengthen a person's skills in this area, they rarely provide an adequate foundation. Also, ensure that the institution granting the degree is a reputable one.

\section{Experience:}

- How long have you been doing test development and validation? Can you describe some selection procedures you developed and the process you used to develop them?

- How are these instruments being used currently?

- How do you evaluate the effectiveness of your work?

- Who are some of your other clients?

- What would I need to know to ensure that a process you developed or sold to me was valid?

- With what kinds of employee populations have you worked?

- With what kinds of industries have you worked?

- What kind of experience do you have defending selection programs?

Comment: Most industrial and organizational psychologists learn how to conduct test validation studies by working with others. In general, an employer does not want to be the first "guinea pig." Explore with consultants the kinds of testing experience they have had as well as the industries and cultures with which they have worked. Also, find out if a potential consultant has experience defending selection instruments and programs against legal and other challenges. Good selection programs may be legally challenged, and a challenged instrument should not be a reason to avoid a consultant. In fact, most organizations want to use a consultant who fully understands the legal issues regarding selection.

\section{Professional Credentials:}

- With which professional organizations are you a member?

- What is your ethics code? Who enforces that ethics code?

Comment: One way to find a testing professional is to look for members of professional organizations such as the Society for Industrial and Organizational Psychology (www.siop.org) that represent a large group of people who are trained in this area. Ethics are an important consideration when personal information about an individual's capabilities is collected. Members of SIOP must subscribe to the American Psychological Association's Code of Ethical Conduct. The American Psychological Association enforces the Code. 
gruntled. Furthermore, applicants may be reluctant to share their true feelings regarding the recruiting and selection process. Consequently, many decisions are based on intuition rather than facts.

\section{Summary}

We have very briefly highlighted four areas in staffing where gaps between research and practice exist, noting both knowledge gaps and implementation gaps. To aid the HR manager in evaluating how well a staffing system fits with current research knowledge, Table $\mathrm{V}$ presents a list of audit questions.

Our goal is to assist the reader in not only understanding the present gaps between research and practice in recruitment and selection, but also in developing skills for employing research in HR practice. We close with three recommendations for the HR professional.

- Use a professional. The world of psychological research in general can be difficult to understand, and selection research is particularly arcane. In fact, not all psychologists understand all areas of research! It takes years of education and experience for an industrial and organizational $(\mathrm{I} / \mathrm{O})$ psychologist to master recruiting and selection. Consequently, HR professionals cannot be expected to achieve the same level of mastery quickly. An $\mathrm{I} / \mathrm{O}$ psychologist who is an expert in recruiting or selection research can assist in translating research into effective practice.

Finding an expert is not difficult; finding a good one can be. Be sure to find one who can explain research, understands your organizational environment, and has experience in real-world settings. Table VI contains a brief list of questions to aid the HR professional in ascertaining the competence of experts.

- Educate yourself and critically evaluate. We do not advocate that most HR professionals subscribe to journals that report research studies, as lack of time and background expertise will make it difficult to gain value from these. We do suggest that you find ways to stay current on what is taking place in the fields of recruitment and selection. That may mean reading broadly, taking a class, or attending a lecture. Regardless of how you stay up-to-date, we recommend that you think critically about all you find (Edwards, Scott, \& Raju, 2003). Table VII presents a list of questions to assist in the evaluation of research.

- Systematically collect data and evaluate efforts. Many of the misconceptions in HR practice are due to mistaken beliefs about what is actually happening. Accurate information is a requirement for understanding what is taking place and making correct interpretations of the facts and careful evaluations. While data collection can be a difficult process in many organizations, new technology can greatly simplify the process and capture much information with little effort on the part of staffing personnel.

TABLE VII Questions for Evaluating Research

- Was the research conducted on a population similar to yours?

- Does the sample appear large enough to have produced stable results?

- Are the conditions under which the research was conducted similar enough to yours to warrant use of the finding?

- Are other explanations of the results also plausible?

- Are the findings strong enough to warrant use of the results?

- Is the research replicable?

- What is the source of the research? Is it reputable? Did the researcher have a stake in the outcome? 
Ann Marie Ryan is a professor of industrial-organizational psychology at Michigan State University. She is a past president of the Society for Industrial and Organizational Psychology and the current editor of Personnel Psychology. She is widely published in the area of employee selection and has a strong research interest in issues of fairness and hiring processes.

NAncy T. Tippins is president of the Selection Practice Group of Personnel Research Associates (PRA), where she is responsible for the development and execution of firm strategies related to employee selection and assessment. Prior to joining PRA, she spent over 20 years conducting selection research in business and industry. She is active in a number of professional organizations and a past president of the Society for Industrial and Organizational Psychology. She is the associate editor of Personnel Psychology.

\section{REFERENCES}

Barrick, M. R., Mount, M. K., \& Judge, T. A. (2001). Personality and performance at the beginning of the new millennium: What do we know and where do we go next? International Journal of Selection and Assessment, 9, 9-30.

Bobko, P., Roth, P. L., \& Petosky, D. (1999). Derivation and implications of a meta-analysis matrix incorporating cognitive ability, alternative predictors, and job performance. Personnel Psychology, 52, 561-589.

Breaugh, J. A., \& Starke, M. (2000). Research on employee recruitment: So many studies, so many remaining questions. Journal of Management, 26, 405-434.

Edwards, J. E., Scott, J. C., \& Raju, N. S. (2003). The human resources program-evaluation handbook. Thousand Oaks, CA: Sage.

Gilliland, S. W., \& Cherry, B. (2000). Managing customers of selection. In J. F. Kehoe (Ed.), Managing selection in changing organizations (pp. 158-196). San Francisco: Jossey-Bass.

Goldstein, H. W., Yusko, K. P., \& Nicolopoulos, V. (2001). Exploring black-white subgroup differences of managerial competencies. Personnel Psychology, 54, 783-808.

Hattrup, K., Rock, J., \& Scalia, C. (1997). The effects of varying conceptualizations of job performance on adverse impact, minority hiring, and predicted performance. Journal of Applied Psychology, 82, 656-664.

Hazer, J. T., \& Highhouse, S. (1997). Factors influencing managers' reactions to utility analysis: Effects of SD-sub(y) method, information frame, and focal intervention, Journal of Applied Psychology, 82, 104-112.
Higgs, A. C., Papper, E. M., \& Carr, L. S. (2000). Integrating selection with other organizational processes and systems. In J. F. Kehoe (Ed.), Managing selection in changing organizations (pp. 73-122). San Francisco: Jossey-Bass.

Hough, L. M., Oswald, F. L., \& Ployhart, R. E. (2001). Determinants, detection and amelioration of adverse impact in personnel selection procedures: Issues, evidence and lessons learned. International Journal of Selection and Assessment, 9, 152-194.

Huffcutt, A. I., \& Roth, P. O. (1998). Racial group differences in employment interview evaluations. Journal of Applied Psychology, 83, 179-189.

Jayne, M.E.A., \& Rauschenberger, J. M. (2000). Demonstrating the value of selection in organizations. In J. F. Kehoe (Ed.), Managing selection in changing organizations (pp. 123-157). San Francisco: Jossey-Bass.

Latham, G. P., \& Whyte, G. (1994). The futility of utility analysis. Personnel Psychology, 47, 31-46.

Macan, T. H., \& Highhouse, S. (1994). Communicating the utility of human resource activities: A survey of I/O and HR professionals. Journal of Business and Psychology, 8, 425-436.

McDaniel, M. A., Morgeson, F. P., Finnegan, E. B., Campion, M. A., \& Braverman, E. P. (2001). Use of situational judgment tests to predict job performance: A clarification of the literature. Journal of Applied Psychology, 86, 730-740.

Murphy, K. R., Osten, K., \& Myors, B. (1995). Modeling the effects of banding in personnel selection. Personnel Psychology, 48, 61-84.

Ployhart, R. E., \& Ehrhart, M. G. (2002). Modeling the practical effects of applicant reactions: Subgroup differences in test-taking motivation, test 
performance, and selection rates. International Journal of Selection and Assessment, 10, 258-270.

Posthuma, R. A., Morgeson, F. P., \& Campion, M. A. (2002). Beyond employment interview validity: A comprehensive narrative review of recent research and trends over time. Personnel Psychology, 55, 1-81.

Roth, P. L., \& Bobko, P. (2000). College grade point average as a personnel selection device: Ethnic group differences and potential adverse impact. Journal of Applied Psychology, 85, 399-406.

Ryan, A. M., \& Ployhart, R. E. (2000). Applicants' perceptions of selection procedures and decisions: A critical review and agenda for the future. Journal of Management, 26, 565-606.

Rynes, S. L., Brown, K. G., \& Colbert, A. E. (2002). Seven common misconceptions about human resource practices: Research findings versus practitioner beliefs. Academy of Management Executive, 16(3), 92-102.

Rynes, S. L., Colbert, A. E., \& Brown, K. G. (2002). HR professionals' beliefs about effective human resource practices: Correspondence between research and practice. Human Resource Management, 41, 149-174.

Sackett, P. R., \& Ellingson, J. E. (1997). The effects of forming multi-predictor composites on group differences and adverse impact. Personnel Psychology, 50, 707-721.

Sackett, P. R., \& Roth, L. (1991). A Monte Carlo examination of banding and rank order methods of test score use in personnel selection. Human Performance, 4, 279-295.

Sackett, P. R., \& Roth, L. (1996). Multi-stage selection strategies: A Monte Carlo investigation of effects on performance and minority hiring. Personnel Psychology, 49, 549-562.

Sackett, P. R., Schmitt, N., Ellingson, J. E., \& Kabin, M. B. (2001). High stakes testing in employ- ment, credentialing, and higher education: Prospects in a post-affirmative action world. American Psychologist, 56, 302-318.

Schmidt, F. L., \& Hunter, J. E. (1998). The validity and utility of selection methods in personnel psychology: practical and theoretical implications of 85 years of research findings. Psychological Bulletin, 124, 262-274.

Schmitt, N., \& Chan, D. (1998). Personnel selection: A theoretical approach. Thousand Oaks, CA: Sage.

Schmitt, N., Rogers, W., Chan, D., Sheppard, L., \& Jennings, D. (1997). Adverse impact and predictive efficiency of various predictor combinations. Journal of Applied Psychology, 82, 719-730.

Society for Industrial and Organizational Psychology. (2003). Principles for the validation and use of personnel selection procedures. Bowling Green, OH: Society for Industrial and Organizational Psychology.

Taylor, M. S., \& Collins, C. J. (2000). Organizational recruitment: Enhancing the intersection of research and practice. In C. L. Cooper \& E. A. Locke (Eds.), Industrial and organizational psychology: Linking theory with practice (pp. 304-330). Oxford, UK: Blackwell.

Terpstra, D. E., \& Rozell, E. J. (1993). The relationship of staffing practices to organizational level measures of performance. Personnel Psychology, 46, 27-48.

Tippins, N. T. (2002). Issues in implementing largescale selection programs. In J. W. Hedge \& E. D. Pulakos (Eds.), Implementing organization interventions: Steps, processes, and best practices (pp. 232-269). San Francisco: JosseyBass.

Whyte, G., \& Latham, G. (1997). The futility of utility analysis revisited: When even an expert fails. Personnel Psychology, 50, 601-610. 